\title{
Struggling With Aging and Illness: Life Experiences of Elderly Schizophrenia Patients in the Community of Taiwan
}

\author{
Wen-Kuei Liao ${ }^{1,2}$ \& Jiin-Ru Rong ${ }^{2}$ \\ ${ }^{1}$ Department of Nursing, St. Mary's Junior College of Medicine, Nursing and Management, Yilan, Taiwan \\ ${ }^{2}$ School of Nursing, National Taipei University of Nursing and Health Sciences, Taipei, Taiwan \\ Correspondence: Jiin-Ru Rong, School of Nursing, National Taipei University of Nursing and Health Sciences, \\ No.365, Ming-te Road, Peitou District, Taipei, Taiwan. Tel: 886-228-227-101-3187.
}

Received: January 8, 2020

Accepted: February 17, 2020

Online Published: March 2, 2020

doi:10.20849/ijsn.v5i1.699

URL: https://doi.org/10.20849/ijsn.v5i1.699

\begin{abstract}
Aims: The number of elderly patients with schizophrenia in Taiwan has increased significantly. Most Taiwanese patients with schizophrenia are community-dwelling and, if elderly, are at increased risk of mental illness and mental health problems. The life experiences of community-dwelling elderly patients dealing with schizophrenia in Taiwan have not been well studied. This study aimed to explore the lived experiences of such patients through in-depth interviews.

Methods: This qualitative study was carried out in psychiatric hospital day-care centers in Taiwan. We interviewed 16 patients ( 9 men and 7 women, mean age $=60.43$ years, $\mathrm{SD}=5.53$ years). Data were analyzed using Colaizzi's method of analysis.

Results: The five major themes pertaining to the life experiences of community-dwelling elderly schizophrenia patients were identified as: 1) living alone, feeling lonely, and caring for myself; 2) anxiety and pessimism about the future; 3) internal conflict and aging; 4) seeking help; 5) delaying needs and engaging in healthy activities.

Conclusions: The community-dwelling elderly schizophrenia patients were worried about the deterioration of their health, loss of self-care ability with aging, and decreasing access to community support and resources while striving to maintain their lives in the community. Mental health care professionals should understand the needs and abilities of patients, and help them to continue to live in the community. In addition to accepting continuous treatment, the patients should be encouraged to maintain healthy behaviors as well as enhance functioning and quality of life.
\end{abstract}

Keywords: elderly patient, schizophrenia, life experience

\section{Introduction}

Schizophrenia is a serious mental illness with cognitive, affective, psychotic, and behavioral symptoms. The course of the disease is chronic. Like other people, patients with chronic schizophrenia grow up, mature, age, and die, but due to long-term use of their medications and disease-related health problems, their life expectancy is usually 14 to 20 years shorter than that of the average person (Dieset, Andreassen, \& Haukvik, 2016; Hjorthøj, Stürup, McGrath, \& Nordentoft, 2017; Jeste \& Maglione, 2013; Laursen, Nordentoft, \& Mortensen, 2014; Nordentoft et al., 2013). Aging begins earlier in patients with schizophrenia. In many countries, patients above the age of 55 are regarded as elderly. As these patients age $20 \%$ faster than the average person, they often have to face the health impacts of aging earlier (Nguyen, Eyler, \& Jeste, 2017; Jeste \& Maglione, 2013). Furthermore, since the symptoms of schizophrenia usually appear during the teenage or early adulthood period, this means that most patients above the age of 55 have been schizophrenic for 20 to 30 years. The physiological, psychological, and social impacts of schizophrenia and premature aging on the patients' lives are different when compared with the impacts of problems and challenges faced by the general elderly population (Ibrahim, Cohen, \& Ramirez, 2010). In Taiwan, National Health Insurance reimbursements allow schizophrenia patients to obtain antipsychotics and seek rehabilitation treatment at psychiatric hospitals on a regular basis. Like other patients with chronic diseases, schizophrenia patients are able to control their symptoms and extend their life expectancy. Therefore, the population of elderly with schizophrenia who are seeking antipsychotic treatment on a regular basis has increased (Pan, Kuo, \& Yeh, 2019). Meanwhile, most of the elderly with schizophrenia who return to 
their communities are rejected by their family members or neighbors and face stigmatization and negative attitudes (Ogden, 2014b).

In addition, as patients become older, they are weakened by their increasingly complex health problems. In reality, to live in their communities, these patients require care, support, and assistance. Health care professionals need to help elderly patients improve their ability to cope with schizophrenia and aging. However, there is a lack of in-depth research on the lives of elderly patients affected by schizophrenia and aging, as well as their lived experiences. Research on these topics should be conducted in the future, so as to help patients acquire the care they need (Avieli, Mushkin, Araten-Bergman, \& Band-Winterstein, 2016; Cohen \& Murante, 2018).

The negative symptoms and chronic health problems associated with schizophrenia often appear early and therefore affect self-care, social functioning, interpersonal interactions, activities of daily living, and problem-solving abilities of these community-dwelling patients, even after treatment (Van Liempt, Dols, Schouws, Stek, \& Meesters, 2017). Even when the positive symptoms of schizophrenia are not obvious, the prevalence of chronic diseases such as cardiovascular disease and metabolic syndrome increases with age. In addition, the loss of bodily functions or abilities and the development of cognitive impairments affect the patients' quality of life (Niimura et al., 2011; Ösby, Westman, Hällgren, \& Gissler, 2016). Furthermore, many patients remain unmarried or childless throughout their adulthood and are cared for by their parents. When these parents become older or less mobile, they lose their ability to care for their schizophrenic children (Gater et al., 2014; Von Kardorff, Soltaninejad, Kamali, \& Eslami Shahrbabaki, 2016; Yang, Hsieh, Lee, \& Chen, 2017). As a result, the increasing burden on family members will affect the patients' safety and quality of life in the community, and also increase unplanned medical costs and consumption (Pan et al., 2019).

The impairments in daily functioning experienced by elderly patients with schizophrenia in their later years may differ from those experienced by the general elderly population. Even when the burden of such impairments is lighter compared to that of the general elderly population, these patients lack the internal and external support and flexible coping strategies to overcome the stress of daily living and improve their adaptive capacity (Ibrahim et al., 2010; Shepherd et al., 2010). Community-dwelling elderly patients with stable symptoms of schizophrenia often have to face the stress of having insufficient resources to meet their daily living needs. Consequently, they have to cope with both the disease and the problems of daily living such as preparing meals, bathing, doing laundry, housecleaning, seeking treatment, and taking medications all on their own. Furthermore, because they lack practical internal and external strategies and resources to cope with stress, elderly patients with schizophrenia struggle to maintain their quality of life.

In light of the lack of studies exploring the experiences of community-dwelling elderly with schizophrenia and the challenges they face, we aimed to investigate them.

\section{Method}

\subsection{Research Design}

This study used phenomenological methods to explore the lived experiences of community-dwelling elderly with schizophrenia. The phenomenological research approach emphasizes looking at things from the perspective of the parties involved in order to explore, describe, and analyze the meaning of the lived experiences (Eatough \& Smith, 2008).The meaning of the lived experiences of community-dwelling elderly patients with schizophrenia was explored using a semi-structured interview guideline (Table 1).

Table 1. Semi-structured interview guideline

1. Can you tell me about your lived experience and feelings as an older adult with schizophrenia?

2. Whether you are living in the community alone or with family, what assistance do you need in your daily life?

3. If you need help, how do you ask for help to deal with stresses or challenges (such as health problems related to schizophrenia and/or aging, as well as more general life stresses)?

\subsection{Data Collection}

This study was with all due consideration given to respecting the participating patients' wishes and privacy. After obtaining the patients consent, the researcher collected the data by face-to-face in-depth interviews conducted from July to December 2018 in a city in northeastern Taiwan. This study used purposive sampling, and the 
inclusion criteria for the participants were: (1) age of at least 55 years or older and diagnosis of schizophrenia or schizoaffective disorder; (2) ability to speak Mandarin or Taiwanese; and (3) continued acceptance of mental rehabilitation treatment. The exclusion criteria were: (1) severe cognitive impairment and (2) drug abuse or alcohol abuse. The interviewer explained the purpose, procedures, and scope of the whole study and the related recordings before the interview. After the participant signed the consent form, he or she took about 30 60 minutes to complete the first interview, which had a semi-structured format, in a quiet and undisturbed place of his or her own choosing. Each interviewee was interviewed at least twice. When no new themes of new lived experiences could be identified, the data were considered saturated.

\subsection{Data Analysis}

The aim of our approach was to allow the participants in the community to interpret the phenomena of their lived experiences. Therefore, this study used Colaizzi's (1978) method of phenomenological analysis in order to better understand the subjective lived experiences of elderly patients with schizophrenia. Two researchers analyzed the data of this study independently, and then compared the meanings of themes and subthemes to one another. The researchers read through the interview transcripts looking for specific issues and identify all of the statements directly related to a given phenomenon in each verbatim transcript, and clarify the meaning of these important statements. Emerging statements, subthemes and themes were categorised and integrated by reviewing the interrelationships between units of meaning. During this process, subthemes and themes were repeatedly compared for similarities, differences, and relationships. Finally, researchers identified five themes in the lived experiences of community-dwelling elderly with schizophrenia.

\subsection{Trustworthiness}

The researchers used four components of trustworthiness to assess the rigor of the research and ensure the trustworthiness of the research process: (a) credibility, (b) transferability, (c) dependability, and (d) confirmation (Lincoln \& Guba, 1985). To establish credibility, we conducted in-depth interviews in Mandarin and Taiwanese, thereby facilitating the participants' descriptions of their lived experiences in the community. After extracting the data from the transcripts, the two authors analyzed and coded the data to reduce the involvement of subjectivity and increase the dependability of the data. To that end, the researchers underwent training in the use of qualitative methods. Furthermore, the two researchers checked and discussed the data analyses to determine how to eliminate subjective perceptions, thereby revealing the real implications of the data. To ensure the data's relevance, recruitment was limited to community-dwelling elderly with schizophrenia, had different lived experiences, and were willing to share their experiences. During the interview process, researcher maintained objectivity, made no subjective judgments, and allowed the participants to fully express their experiences. The researchers regularly discussed the interview process to clarify relevant ideas and ensure objectivity, and used self-reflection to reduce the impact of research bias. During the study, participants were asked to clarify any unclear statements to ensure the truth and integrity of the information.

\subsection{Ethical Considerations}

This study was approved by the Research Ethics Committee of a psychiatric hospital in Taiwan (No: YLH-IRB-10708), respecting the patient's wishes and privacy, and informing the participants about the purpose of the research and the duration of the interview, the researcher obtained signed consent forms from the interviewees. Participants could leave from the study at any time. As for the participating patient's data, the researchers are responsible for maintaining the confidentiality of the patient's data.

\section{Results}

The study included 16 patients aged between 55 and 75 years old (Table 2), all of whom were able to share their lived experiences. The main theme of this study revealed struggling with aging and illness. Five themes pertaining to the life experiences of community-dwelling elderly with schizophrenia, as living alone, feeling lonely, and caring for myself; anxiety and pessimism about the future; internal conflict and aging; seeking help; and delaying needs and engaging in healthy activities. The themes are shown in Table 3.

Table 2. Participant characteristics and demographic data $(\mathrm{N}=16)$

\begin{tabular}{llll}
\hline Participant & Diagnosis & Gender & Age \\
\hline 1 & Schizophrenia & Male & 56 \\
\hline 2 & Schizophrenia & Male & 56 \\
\hline
\end{tabular}




\begin{tabular}{llll}
\hline 3 & Schizoaffective disorder & Female & 60 \\
\hline 4 & Schizophrenia & Male & 55 \\
\hline 5 & Schizophrenia & Female & 65 \\
\hline 6 & Schizoaffective disorder & Female & 55 \\
\hline 7 & Schizophrenia & Male & 56 \\
\hline 8 & Schizoaffective disorder & Female & 57 \\
\hline 9 & Schizophrenia & Female & 64 \\
\hline 10 & Schizophrenia & Male & 63 \\
\hline 12 & Schizophrenia & Male & 66 \\
\hline 13 & Schizophrenia & Male & 75 \\
\hline 14 & Schizophrenia & Female & 58 \\
\hline 15 & Schizophrenia & Male & 65 \\
\hline 16 & Schizophrenia & Male & 56 \\
\hline
\end{tabular}

Table 3. Themes of struggling with aging and illness of elderly schizophrenia patients

\begin{tabular}{|c|c|}
\hline Theme & Subtheme \\
\hline \multirow[t]{4}{*}{$\begin{array}{l}\text { 3.1 Living alone, feeling lonely, } \\
\text { and caring for myself }\end{array}$} & $\begin{array}{l}\text { 3.1.1 Performing life activities, such as preparing meals, washing } \\
\text { clothes, taking out garbage, and cleaning, on one's own }\end{array}$ \\
\hline & $\begin{array}{l}\text { 3.1.2 Going to see the doctor and dealing with complex health } \\
\text { problems on one's own }\end{array}$ \\
\hline & 3.1.3 Handling one's own medication \\
\hline & 3.1.4 Participating in rehabilitation activities \\
\hline \multirow[t]{2}{*}{$\begin{array}{l}\text { 3.2 Anxiety and pessimism about } \\
\text { the future }\end{array}$} & $\begin{array}{l}\text { 3.2.1 Fear of memory loss, physical weakness, and becoming } \\
\text { dependent }\end{array}$ \\
\hline & $\begin{array}{l}\text { 3.2.2 Low confidence in one's ability to execute daily living } \\
\text { functions }\end{array}$ \\
\hline \multirow[t]{3}{*}{ 3.3 Internal conflict and aging } & $\begin{array}{l}\text { 3.3.1 Living with and controlling the residual symptoms of } \\
\text { schizophrenia }\end{array}$ \\
\hline & 3.3.2 Appraisal of threats relating to life in old age \\
\hline & $\begin{array}{l}\text { 3.3.3 Avoiding stigmas and conflicts, while attempting to engage } \\
\text { with people who have friendly attitudes toward others }\end{array}$ \\
\hline \multirow[t]{2}{*}{ 3.4 Seeking help } & 3.4.1 Asking for help in getting treatment and living assistance \\
\hline & 3.4.2 Looking for long term care facility arrangements \\
\hline \multirow{2}{*}{$\begin{array}{l}3.5 \text { Delaying needs and engaging } \\
\text { in healthy activities }\end{array}$} & 3.5.1 Perceiving the unhealthy habits impact to personal health \\
\hline & 3.5.2 Change unhealthy habits and maintain health behavior \\
\hline
\end{tabular}

\subsection{Theme 1: Living Alone, Feeling Lonely, and Caring for Myself}

Older people with schizophrenia usually live alone in the community. Some patients live with their families; however, most of the time, patients still feel lonely, and they face the problems and challenges of self-care alone.

3.1.1 Performing Life Activities, Such as Preparing Meals, Washing Clothes, Taking Out Garbage, and Cleaning, on One's Own

Patients had to deal with and handle daily living tasks. 
"I have to buy my own meals, do laundry, and take out the trash every couple of days... There's a lot to do and it's difficult to keep things orderly."(P5)

"Every day, after having dinner, I have to sweep and mop the floor, do laundry, and take out the trash... all by myself."(P14)

3.1.2 Going to See the Doctor and Dealing With Complex Health Problems on One's Own

The patients made visits to the doctor or addressed other health problems by themselves.

"I don't have much mobility because of an old waist injury. I have to walk slowly and wear a waist support belt to alleviate the pain. I even have to take painkillers sometimes."(P11).

"I'm old now and I have to deal with the bone spur on my foot. It gets painful when it's cold, so I go to the doctor for treatment and take medications to ease the pain."(P16)

\subsubsection{Handling One's Own Medication}

The patients had to encourage themselves daily to self-administer their medications.

"I'm getting older and have hypertension; I don't want to have a stroke. I would put the medicines into

a pill organizer on the table to remind and train myself to take them every day. This way, I would always remember to take the medications."(P2)

"I am a schizophrenia patient, my therapist trained me take anti-psychotic medication regularly; therefore, I cannot change the medications by my idea, as this would cause discomfort and psychiatric symptoms."(P9)

3.1.4 Participating in Rehabilitation Activities

The patients regularly participated in psychiatric rehabilitation activities.

"I come to the hospital to take part in the daily activities. Attending lessons at the day care center has made me less inactive."(P5)

"I have some friends day-care centers. We join the activities, clean the place, and watch television together. Being able to chat feels good and the days get better. I come every day as I like the clean and tidy environment here."(P13)

\subsection{Theme 2: Anxiety and Pessimism About the Future}

The participating patients expressed anxiety and pessimism about the future. Their concerns related to becoming dependent on others, having low daily living self-efficacy, and being ashamed of having schizophrenia.

3.2.1 Fear of Memory Loss, Physical Weakness, and Becoming Dependent

Some of the participating patients had a fear of becoming dependent due to memory problems, cognitive impairment, and physical weakness.

"I am unable to work because I am easily distracted by my thoughts, I don't know what I'm thinking...

I do everything slowly. My memory has deficits and decline."(P6)

"My responses have become slower, as if my brain is disconnected and blank... I can't think clearly and I can't remember my thoughts. It has gotten worse as I get older. I am afraid that my condition will continue to decline." $(P 9)$

"I am afraid that my memory and physical condition will continue to decline, and I need to depend on others to care me. However, I don't know how to seeking long term care resources." (P13)

\subsubsection{Low Confidence in One's Ability to Execute Daily Living Functions}

Some of the participating patients thought that they were too frail to engage in regular social and daily activities. Their frailty impeded their ability to perform self-care and engage in social activities.

"I'm worried that I have a lot of health problems. Relying on my family for care places a huge burden on them. I need to look after myself on my own, but my ability to do so is very limited."(P10)

"I feel weak and in pain all the time. I've been schizophrenic for 30 years already. I am weakness and unable to take care of myself."(P15)

\subsection{Theme 3: Internal Conflict and Aging}

Some of the participating elderly schizophrenia patients expressed difficulties with learning how to convert stigma and challenge into hope and optimism. 


\subsubsection{Living With and Controlling the Residual Symptoms of Schizophrenia}

The patients tried hard to control their residual symptoms and coexist with them.

"I have schizophrenia and take medications to control the psychiatric symptoms."(P3)

"Being on antipsychotic medications makes me weak, But I cycle every day to maintain my strength, and rest when I'm tired."(P12)

3.3.2 Appraisal of Threats Relating to Life in Old Age

The patients had to assess the perils of old age.

"As I get older, I suffer from more and more chronic diseases. I might need to rely on others to take care of me. Therefore, now that I still have the strength and ability, I would rather work to save some money for the future."(P10)

3.3.3 Avoiding Stigmas and Conflicts, While Attempting to Engage With People Who Have Friendly Attitudes Toward Others

Some patients were stigmatized for being schizophrenic and aging. In order to avoid conflicts with others and to prevent the stigmatization of schizophrenia, patients are willing to approach friendlier people and therapeutic resources.

"Other people will make fun of my condition. They say I'm abnormal and they don't want to talk to me and look down on me. It's better for me to stay away from them."(P1)

"I enjoy going to the day care center. The therapist gives lessons and we exercise, watch television, and sing together. It's a happy feeling. I like being around them. We support each other and we aren't being looked down on or shunned by others."(P4)

"The neighbors are scared whenever they see me, so I seldom go out now. My sister also told me that it's better to stay at home to avoid being disliked or rejected by others."(P5)

\subsection{Theme 4: Seeking Help}

Some of the participating elderly patients talked about seeking therapeutic and living assistance and support.

\subsubsection{Asking for Help in Getting Treatment and Living Assistance}

The patients sought treatment and assistance from others.

"If I have a cold, I ask the nurses for help and they take me to a doctor. I trust the doctors and followtheir instructions." (P3)

"My hands and feet are no longer agile now that I'm older. They're inflexible and my movement have become slower. I need assistance with daily activities and personal care."(P5)

\subsubsection{Looking for Long Term Care Facility Arrangements}

The patients looked forward to having daily care assistance or to checking into a long-term nursing care institution.

"I often have conflicts with my brother. He has his own family. I'm worried that when I'm getting older, no one will look after me. I wish to stay in a nursing home until to I die."(P8)

\subsection{Theme 5: Delaying Needs and Engaging in Healthy Activities}

Some of the participating elderly patients discussed being aware that their habits had negative impacts on health, and using positive self-talk to change unhealthy behaviors and maintain health by engaging in healthy activities.

\subsubsection{Perceiving the Unhealthy Habits Impact to Personal Health}

The patients were able to aware and identify their unhealthy habits to their health.

"I love fried chicken fillet and bubble tea. However, consuming too many sugary beverages is bad for my health. I'm afraid that I might get a stroke or become diabetic when I'm older. I am able to control these temptations now. I stay away from such beverages and only drink water."(P7)

\subsubsection{Change Unhealthy Habits and Maintain Health Behavior}

Patients encourage and support themselves to develop healthy behavior for maintaining health functioning.

"I use an alarm clock since I always feel sleepy. I tell myself that I am able to do it. I can get out of bed on my own without relying on others to call me. I am able to control my emotions now. I tell myself not to throw a 
tantrum all the time." (P9)

"I keep my spending under control. I tell myself to just carry less cash around and save money for future needs." (P12)

\section{Discussion}

Searching for assistance is a painful challenge for someone who is aging and living with schizophrenia. The conflict between psychiatric symptoms and reality is a never-ending source of suffering in patients with schizophrenia who, as a result, must exert considerable effort to maintain their lives in the community. Patients must overcome problems associated with the disease, control their desires, try to control their fear of stigmatization, and learn how to seek assistance with maintaining their lives in the community (Martinsson, Fagerberg, Lindholm, \& Wiklund-Gustin, 2012; Rastad, Martin, \& Asenlof, 2014). The elderly with schizophrenia in this study were mostly living alone in the community. Even though some of the patients lived with their families, their interactions were limited as the patients generally managed their own daily living tasks, such as preparing meals, washing clothes, visiting doctors, taking medications, and participating in mental rehabilitation activities. This study produced findings similar to those of previous studies. Topics such as "the heaviness of being alone" and "I would get on with it myself" reveal the loneliness of patients as they deal with their own problems (Quin, Clare, Ryan, \& Jackson, 2009). In addition, living alone in the community left patients feeling detached from society and less socially interactive (Avieli et al., 2016; Ogden, 2014b). Even though these scenarios are also life experiences of the general elderly population, studies have shown that patients with schizophrenia face more challenges to aging in place and successful aging. Therefore, professional caregivers should help schizophrenia patients prepare for living in the community as they getting old (Ibrahim et al., 2010; Niimura et al., 2011).

The elderly with schizophrenia in this study had anxiety and fear, developed disabilities, and lacked care. As patients were worried about losing their memory, cognitive functions, and physical strength, they lacked the confidence to perform activities of daily living. Moreover, the social stigma of schizophrenia affected the patients' willingness to pursue resources and support from the community. This was similar to previous reports that elderly patients with schizophrenia not only cope with mental impairments arising from the disease but also with physical comorbidities that require regular treatment or self-medication (Avieli et al., 2016; Rastad et al., 2014; Pan et al., 2019). However, economic restrictions and the social stigma of schizophrenia hindered these patients' access to medical and social resources (Fortuna et al., 2017; Tzouvara, Papadopoulos, \& Randhawa, 2018). Anxiety and depression developed as a result of feeling isolated and hopeless about the future, or from lacking the ability to solve problems (Roepke \& Seligman, 2016). According to the cognitive model of depression and research findings in those with negative expectations regarding future events, such people will have lower expectations of life and have higher rates of attempted suicide (Roepke \& Seligman, 2016; Cohen, Abdallah, \& Diwan, 2010). This indicates that the care given to elderly patients with schizophrenia should not be only focused on their mental conditions, medications, and behavioral problems, but should also include assistance in seeking treatment for physical comorbidities and chronic diseases. In addition, caregivers should be attentive to and care for the emotional problems of patients, such as anxiety, depression, and self-harm or suicidal tendencies.

In this study, the average period since diagnosis of schizophrenia was 30 years. The patients reported their struggles with the disease and life in general. Affected by schizophrenia-related symptoms, pressures of life, and survival, the experiences of patients in this study are in line with those of community-dwelling elderly patients with schizophrenia in Western nations. In their struggles to resign themselves to suffering from the illness, the patients seemed to develop various coping strategies (Kaite, Karanikola, Merkouris, \& Papathanassoglou, 2015). These studies further suggest that psychiatric mental health care professionals should assist elderly schizophrenia patients to develop coping skills to deal with the challenges of community life, such as the skill needed to adhere to a self-medication regimen, control impulsive reactions, and resist illness social stigma. With regard to the pressures they face in life, patients coping with schizophrenia and overcoming the problems and difficulties of aging should cultivate a positive attitude (Ogden, 2014a).

Community-dwelling elderly patients with schizophrenia had difficulties in obtaining immediate assistance from caregivers or family and friends. At the same time, the combined effects of chronic schizophrenia and aging impaired self-care abilities and strategies for coping with the stresses in life. As a result, they faced difficulties in obtaining the resources needed for living in the community (Avieli, Mushkin et al., 2016). The elderly patients interviewed in this study expressed their desire for help in getting treatment and living assistance. The relevant literature emphasizes that professionals should pay more attention to the need for continuous treatment of schizophrenia in elderly patients, especially the effects of age on the disease process, the side effects of 
medications, and the goals and effects of psychosocial interventions (Jeste \& Maglione, 2013). The care needs of elderly patients with schizophrenia are different from those of younger adult patients with the disease. Professionals need to know that the positive symptoms tend to be less severe in elderly patients than in younger adult patients, and that physical comorbidity is common in elderly patients (Ko, Smith, Liao, \& Chiang, 2014). Moreover, older age is a risk factor for the side effects of antipsychotics (Jeste \& Maglione, 2013). The results of this and previous studies also support the view that patients and their caregivers should be informed about physical problems and antipsychotic drug side effects in older adults (Jeste \& Maglione, 2013). In addition, these patients and their families will need resources to help them plan or transition to long-term care living arrangements. However, in a previous study, only half of the elderly patients identified as having mental illnesses received adequate care (Rosenblatt et al., 2004). Therefore, geropsychiatric professionals need to help elderly patients with psychosis find support networks and long-term care services.

In this study as well as previous qualitative studies, patients emphasized the importance of engaging in healthy activities. Relatedly, elderly patients with schizophrenia who took part in physical exercise generally benefited. To preserve and promote well-being and reduce health problems, professionals need to provide patients with healthy activities to engage in (Blomqvist, Sandgren, Carlsson, \& Jormfeldt, 2018; Leutwyler, Hubbard, Slater, \& Jeste, 2014).

The care of patients with schizophrenia in Taiwan is focused on the treatment of psychiatric symptoms and the control of psychologically problematic behaviors. However, in recent years, with the aging of the patient population and the growth of community mental health care services, elderly psychotic patients have increasingly required continuous access to long-term care services after returning to the community. At the same time, only a few published studies have focused on the life experiences of elderly community-dwelling patients with schizophrenia. So, the present study explored their community life needs. Moreover, providing assistance to deal with the impacts of chronic schizophrenia and arranging long-term care services remain important issues that need to be addressed on a continuous basis.

\section{Conclusion}

The literature on patients with schizophrenia emphasizes that patients will accelerate aging process, and chronic health problems usually appear early, and these will affect the cognitive decline,and poor self-care ability (Kirkpatrick, Messias, Harvey, Fernandez-Egea, \& Bowie, 2008); moreover, patients must overcome problems associated with the disease and learn how to self-care with maintaining their lives in the community (Avieli et al., 2016; Rosenblatt et al., 2004; Rastad et al., 2014; Thuaire et al., 2020). This is consistent with the results of this study that community-dwelling elderly patients with schizophrenia worry about aging, its adverse effect on physiological health and self-care ability, and the decrease in availability of community support and resources. Even though they attempted to control the negative impacts of schizophrenia and also developed healthy habits, they were still worried that they would not be able to care for themselves in the community (Martinsson et al., 2012). Assistance must be provided to help patients in a community setting manage self-care, including activities of daily living, and treatment for mental and physiological health problems. The main results of this study on community-dwelling elderly patients with schizophrenia facing the challenges of disease, aging, and change in lifestyle can serve as a reference for caregivers of such patients and help them to understand the conditions and worries of these patients. These patients should be encouraged to change their lives, learn and implement strategies to enhance their self-care and well-being with the goal of keeping people healthier and living longer in their communities (Kaite et al., 2015).

\section{Study Limitations and Recommendations}

The limitations of this study are mainly the small number of samples and the limitation of the location of the case. The results of the study cannot be inferred to all the elderly schizophrenia patients who live in the community. With regard to future research, community-dwelling elderly schizophrenia patients must be provide assistance to help them enhance their self-care ability. With aging, elderly patients become more aware of the challenges posed by schizophrenia and aging and express a preference not to rely solely on others. Consequently, the patients struggle against the hardships of the disease, the reality of their lives, and maintaining their lives in the community. Hence, care professionals should understand the needs and abilities of patients in order to support their efforts to remain in the community. In addition to providing continuous treatment, healthy behaviors should be encouraged so as to enhance functioning and quality of life.

\section{Acknowledgments}

We express our sincere gratitude to the grant of 106 ntunhs-TR-01 (grant from National Taipei University of Nursing and Health Sciences) for supporting this study. In addition, we are grateful to thank the participants of this study. 


\section{References}

Avieli, H., Mushkin, P., Araten-Bergman, T., \& Band-Winterstein, T. (2016). Aging with schizophrenia: A lifelong experience of multidimensional losses and suffering. Archives of Psychiatric Nursing, 30(2), 230-236. https://doi.org/10.1016/j.apnu.2015.11.005

Blomqvist, M., Sandgren, A., Carlsson, I. M., \& Jormfeldt, H. (2018). Enabling healthy living: Experiences of people with severe mental illness in psychiatric outpatient services. International Journal of Mental Health Nursing, 27(1), 236-246. https://doi.org/10.1111/inm.12313

Cohen, C. I., \& Murante, T. (2018). A prospective analysis of the role of cognition in three models of aging and schizophrenia. Schizophrenia Research, 196, 22-28. https://doi.org/10.1016/j.schres.2017.06.022

Cohen, C. I., Abdallah, C. G., \& Diwan, S. (2010). Suicide attempts and associated factors in older adults with schizophrenia. Schizophrenia Research, 119(1-3), 253-257. https://doi.org/10.1016/j.schres.2010.03.010

Colaizzi, P. F. (1978). Psychological research as the phenomenologist views it. In R. S. Valle, \& M. King (Eds.), Existential-phenomenological alternatives for psychology (pp. 48-71). New York, NY: Oxford University Press.

Dieset, I., Andreassen, O. A., \& Haukvik, U. K. (2016). Somatic comorbidity in schizophrenia: Some possible biological mechanisms across the life span. Schizophrenia Bulletin, 42(6), 1316-1319. https://doi.org/10.1093/schbul/sbw028

Eatough, V., \& Smith, J. A. (2008). Interpretative phenomenological analysis. The Sage Handbook of Qualitative Research in Psychology, 179, 193-211.

Fortuna, K. L., Lohman, M. C., Batsis, J. A., DiNapoli, E. A., DiMilia, P. R., Bruce, M. L., \& Bartels, S. J. (2017). Patient experience with healthcare services among older adults with serious mental illness compared to the general older population. The International Journal of Psychiatry in Medicine, 52(4-6), 381-398. https://doi.org/10.1177/0091217417738936

Gater, A., Rofail, D., Tolley, C., Marshall, C., Abetz-Webb, L., Zarit, S. H., \& Berardo, C. G. (2014). Sometimes it's difficult to have a normal life: Results from a qualitative study exploring caregiver burden in schizophrenia. Schizophrenia Research and Treatment, 1-13. https://doi.org/10.1155/2014/368215

Hjorthøj, C., Stürup, A. E., McGrath, J. J., \& Nordentoft, M. (2017). Years of potential life lost and life expectancy in schizophrenia: a systematic review and meta-analysis. The Lancet Psychiatry, 4(4), $295-301$. https://doi.org/10.1016/s2215-0366(17)30078-0

Ibrahim, F., Cohen, C. I., \& Ramirez, P. M. (2010). Successful aging in older adults with schizophrenia: Prevalence and associated factors. The American Journal of Geriatric Psychiatry, 18(10), 879-886. https://doi.org/10.1097/jgp.0b013e3181d57441

Jeste, D. V., \& Maglione, J. E. (2013). Treating older adults with schizophrenia: Challenges and opportunities. Schizophrenia Bulletin, 39(5), 966-968. https://doi.org/10.1093/schbul/sbt043

Kaite, C. P., Karanikola, M., Merkouris, A., \& Papathanassoglou, E. D. (2015). An ongoing struggle with the self and illness: A meta-synthesis of the studies of the lived experience of severe mental illness. Archives of Psychiatric Nursing, 29(6), 458-473. https://doi.org/10.1016/j.apnu.2015.06.012

Kirkpatrick, B., Messias, E., Harvey, P. D., Fernandez-Egea, E., \& Bowie, C. R. (2008). Is schizophrenia a syndrome of accelerated aging?. Schizophrenia bulletin, 34(6), 1024-1032. https://doi.org/10.1093/schbul/sbm140

Ko, C. J., Smith, P., Liao, H. Y., \& Chiang, H. H. (2014). Searching for reintegration: Life experiences of people with schizophrenia. Journal of Clinical Nursing, 23(3-4), 394-401. https://doi.org/10.1111/jocn.12169

Laursen, T. M., Nordentoft, M., \& Mortensen, P. B. (2014). Excess early mortality in schizophrenia. Annual Review of Clinical Psychology, 10, 425-448. https://doi.org/10.1146/annurev-clinpsy-032813-153657

Leutwyler, H., Hubbard, E. M., Slater, M., \& Jeste, D. V. (2014). It's good for me: Physical Activity in Older Adults with Schizophrenia. Community Mental Health Journal, 50(1), $75-80$. https://doi.org/10.1007/s10597-013-9613-7

Lincoln, Y., \& Guba, E. (1985). Naturalistic inquiry. Newbury Park, CA: Sage.

Martinsson, G., Fagerberg, I., Lindholm, C., \& Wiklund-Gustin, L. (2012). Struggling for existence-life situation experiences of older persons with mental disorders. International Journal of Qualitative Studies on Health and Well-being, 7(1), 1-9. https://doi.org/10.3402/qhw.v7i0.18422

Nguyen, T. T., Eyler, L. T., \& Jeste, D. V. (2017). Systemic biomarkers of accelerated aging in schizophrenia: A critical review and future directions. Schizophrenia Bulletin, 44(2), 398-408. 
https://doi.org/10.1093/schbul/sbx069

Niimura, H., Nemoto, T., Yamazawa, R., Kobayashi, H., Ryu, Y., Sakuma, K., \& Mizuno, M. (2011). Successful aging in individuals with schizophrenia dwelling in the community: A study on attitudes toward aging and preparing behavior for old age. Psychiatry and Clinical Neurosciences, 65(5), 459-467. https://doi.org/10.1111/j.1440-1819.2011.02249.x

Nordentoft, M., Wahlbeck, K., Hällgren, J., Westman, J., Ösby, U., Alinaghizadeh, H., \& Laursen, T. M. (2013). Excess mortality, causes of death and life expectancy in 270,770 patients with recent onset of mental disorders in Denmark, Finland and Sweden. PloS One, 8(1), 1-11. https://doi.org/10.1371/journal.pone.0055176

Ogden, L. P. (2014a). My Life as it is Has Value Narrating Schizophrenia in Later Years. Qualitative Health Research, 24(10), 1342-1355. https://doi.org/10.1177/1049732314546752

Ogden, L. P. (2014b). Interpersonal relationship narratives of older adults with schizophrenia-spectrum diagnoses. American Journal of Orthopsychiatry, 84(6), 674-684. https://doi.org/10.1037/ort0000035

Ösby, U., Westman, J., Hällgren, J., \& Gissler, M. (2016). Mortality trends in cardiovascular causes in schizophrenia, bipolar and unipolar mood disorder in Sweden 1987-2010. The European Journal of Public Health, 26(5), 867-871. https://doi.org/10.1093/eurpub/ckv245

Pan, Y. J., Kuo, K. H., \& Yeh, L. L. (2019). Healthcare cost, service use and mortality in major psychiatric disorders in Taiwan. Journal of Affective Disorders, 246, 112-120. https://doi.org/10.1016/j.jad.2018.12.046

Quin, R. C., Clare, L., Ryan, P., \& Jackson, M. (2009). Not of this world: The subjective experience of late-onset psychosis. Aging and Mental Health, 13(6), 779-787. https://doi.org/10.1080/13607860903046453

Rastad, C., Martin, C., \& Asenlof, P. (2014). Barriers, benefits, and strategies for physical activity in patients with schizophrenia. Physical Therapy, 94(10), 1467-1479. https://doi.org/10.2522/ptj.20120443

Roepke, A. M., \& Seligman, M. E. (2016). Depression and prospection. British Journal of Clinical Psychology, 55(1), 23-48. https://doi.org/10.1111/bjc.12087

Rosenblatt, A., Samus, Q. M., Steele, C. D., Baker, A. S., Harper, M. G., Brandt, J., \& Lyketsos, C. G. (2004). The Maryland Assisted Living Study: Prevalence, recognition, and treatment of dementia and other psychiatric disorders in the assisted living population of central Maryland. Journal of the American Geriatrics Society, 52(10), 1618-1625. https://doi.org/10.1111/j.1532-5415.2004.52452.x

Shepherd, S., Depp, C. A., Harris, G., Halpain, M., Palinkas, L. A., \& Jeste, D. V. (2010). Perspectives on schizophrenia over the lifespan: A qualitative study. Schizophrenia Bulletin, 38(2), 295-303. https://doi.org/10.1093/schbul/sbq075

Thuaire, F., Rondepierre, F., Bacon, E., Vallet, G. T., Jalenques, I., \& Izaute, M. (2020). Executive functions in schizophrenia aging: Differential effects of age within specific executive functions. Cortex, 125, 109-121. https://doi.org/10.1016/j.cortex.2019.12.003

Tzouvara, V., Papadopoulos, C., \& Randhawa, G. (2018). Self-Stigma Experiences Among Older Adults with Mental Health Problems Residing in Long-Term Care Facilities: A Qualitative Study. Issues in Mental Health Nursing, 39(5), 403-410. https://doi.org/10.1080/01612840.2017.1383540

Van Liempt, S., Dols, A., Schouws, S., Stek, M. L., \& Meesters, P. D. (2017). Comparison of social functioning in community - living older individuals with schizophrenia and bipolar disorder: A catchment area - based study. International Journal of Geriatric Psychiatry, 32(5), 532-538. https://doi.org/10.1002/gps.4490

Von Kardorff, E., Soltaninejad, A., Kamali, M., \& Eslami Shahrbabaki, M. (2016). Family caregiver burden in mental illnesses: The case of affective disorders and schizophrenia-a qualitative exploratory study. Nordic Journal of Psychiatry, 70(4), 248-254. https://doi.org/10.3109/08039488.2015.1084372

Yang, C. I., Hsieh, M. Y., Lee, L. H., \& Chen, S. L. (2017). Experiences of caring for a sibling with schizophrenia in a Chinese context: A neglected issue. International Journal of Mental Health Nursing, 26(4), 409-417. https://doi.org/10.1111/inm.12269

\section{Copyrights}

Copyright for this article is retained by the author(s), with first publication rights granted to the journal.

This is an open-access article distributed under the terms and conditions of the Creative Commons Attribution license (http://creativecommons.org/licenses/by/4.0/). 